\title{
Manifestation of the Factor of Regional Median Position
}

\author{
VICTORIA V. AKBERDINA \\ Department of Regional Industrial Policy and Economic Security \\ Institute of Economics of the Ural Branch of the Russian Academy of Sciences \\ 29 Moskovskaya str., Ekaterinburg, 620014 \\ RUSSIAN FEDERATION \\ ALYONA S. SERGEEVA \\ Department of Regional Industrial Policy and Economic Security \\ Institute of Economics of the Ural Branch of the Russian Academy of Sciences \\ 29 Moskovskaya str., Ekaterinburg, 620014 \\ RUSSIAN FEDERATION
}

\begin{abstract}
The article summarises theoretical approaches to determining the median regions, their place and role in the territorial structure of the country and its socio-economic development. The basis of the approach proposed is multiple descriptions of a set of attributes, connections, and relationships, a holistic view of the region as a relatively stable part of the socio-economic space. To conduct an empirical study in Russia, 32 regions were selected, attributed to the category of the median regions by their geographical position. According to the approach, the list of verifiable median characteristics of the regions includes transit, polystructurality, scale, resource availability, gravity, population concentration, the role in ensuring national security, budget donation, the "pilot" character, the concentration of intellectual potential, low risks, high investment and innovation potential, high contact with neighbouring territories, and clustering. The results of the study suggest that the cumulative effect of the regional median position has a significant differentiation. Therefore, the authors can distinguish such types of median regions as integrators of the economic space, sustainable median regions, and developing median regions. Based on the topological attributes of median regions, the mission of median regions is justified. It is substantiated that the factor of the medianness of the region can be of key importance in regional policy only if this resource is used correctly in program activities, regional development strategies and regional policy of the state.
\end{abstract}

Key-Words: - median region, regional structure, topological attributes, cumulative effect, socio-economic space.

\section{Introduction}

The most important factor in the economic development of the region is its position in the country's territorial space. The spatial position is defined as a set of such spatial aspects of the relationship of the object to other objects that are essential for the object in question; the properties of objects depend on their position in space [1]. According to Rodoman [1], there is a force that can be referred to as "place pressure", or "positional pressure".

To date, the literature has accumulated a significant number of studies devoted to the spatial aspects of economic relations and their role in the development of isolated regions of different types.

Theoretical constructions of Losch [2], Weber [3], Launhardt, Christaller [4], Animitsa et al. [5], Tyunen, Isard [6], Kuklinski [7], and others substantiate the importance of the central (median) places of the regions in the formation of the spatial configuration of the territorial socio-economic system $[8,9]$. The median position also favours the development of trade and business infrastructure. Another advantage is the development of production functions that receive natural savings on the transport of resources and goods across the territory of the region or to its borders. Organisational and managerial structures help to increase the homogeneity and integratedness of the regional economic space, thereby allowing economic entities to save on transaction costs.

In this respect, it is very relevant to develop a methodological approach to identifying the median factor of the region, as well as the effects that determine the relationship of the median region to the territory of the entire country. That is why the 
purpose of this research is to substantiate the topological attributes and metric characteristics of the median regions. The authors will consider the attributes of the median regions' development in developed and developing countries. Special attention will be paid to an analysis of the median regions in Russia in view of the country's scale. Using regression models, the authors will show the possibilities of taking into account the median factor in predicting socio-economic development.

\section{Literature Review}

In order to better understand the specifics of the concept "median region", it is necessary to compare it with such a close notion as "central region". The concept of "centre-periphery", the founder of which is considered to be Friedmann $[10,11]$, is of great importance for highlighting the economic characteristics of the median region. According to his theory, uneven economic growth and spatial polarisation inevitably create disproportions between the core (centre) and the periphery. The centre and the periphery at any spatial level are connected by flows of information, capital, goods, labour, etc., and it is the directions of these flows that determine the nature of the interaction between them [12]. The concept of "centre-periphery", transferred to the regional level, was furthered in the work by Gritsay et al. [13]. They distinguish three types of territories (regions): central, semi-peripheral, and peripheral, which arise as a result of the stratification of the economic space and are characterised by a number of specific attributes and development trends.

An analysis of the literature on regional development shows that the notions of "centrality" and "medianness" play an important role in many theories of production organisation. However, the median region differs from the central one (although they may theoretically coincide) in that the first is not necessarily located in the historical centre of the country and is not always endowed with all the high administrative and managerial functions. Animitsa [14] interprets the definition of the median region as a special, state-forming type of a large region that develops in the central, strategically important part of the country and has a set of specific topological attributes. Tatarkin [15] denotes the median region as being situated, located in the middle of the country's territory or other space that is larger than the median region.

By the median region, the authors mean a complex hierarchical system in the multi-level territorial structure of the country, which includes both a territorial physical basis located in a geographical position remote from borders and an integral set of relationships and dependencies that arise in a combination of a system-forming role in the socio-economic development of the state and participation in ensuring national security.

In contrast to the well-known concepts of 'median region', author's interpretation takes into account the median factor not only in geographic location, but also through a set of relations developing between economic agents, integrated structures, institutions and the government.

The development and expansion of management and organising functions (production, social, political, and other) in the median region is an important median characteristic. This in turn leads to imbalances and socio-economic differentiation. Pavlov [16] emphasises the significant impact of imbalances in reproduction on the socio-economic system of the region. From the point of view of Shniper [17], an analysis of production-economic and social imbalances at the regional level is based on the main provisions of the structural and functional approach. According to the theory of socio-economic differences, balanced regional reproduction is possible only when, along with the mechanism of forming proportions, there is a mechanism of qualitative transformations of relations inherent in the given economic system (Maevsky [18], Brodskaya [19]).

Determining the growth poles is a serious concern and is needed to encourage the sustainability of economic growth between regions [27]. For this reason, there is a logical demonstration, and rationality of the analysis used (Klassen's Typology, Williamson Index and Gravity Index) is needed to answer the study problem [28, 29]. The analysis models cannot be combined, but rather aim to solve different problems.

All this leads to the need for a comprehensive study of the imbalances in regional development, determining the causes, factors, and conditions of economic development, their quantitative assessment, as well as searching for ways to eliminate these imbalances.

\section{Materials and Methods}

An analysis of approaches to the essence of the median region makes it possible to identify the classification groups of the median region's attributes (spatial location, administrative component, socioeconomic component, interactions) and supplementing the traditional topological attributes with new ones (Table 1). 
Table 1. Topological attributes of the median regions

\begin{tabular}{|c|c|c|c|}
\hline Type & Attribute group & Main attributes & Additional attributes \\
\hline \multirow{2}{*}{ 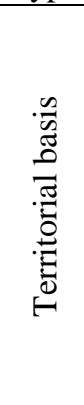 } & Spatial extent & $\begin{array}{c}\text { Scale } \\
\text { Position in the "middle" } \\
\text { Transit } \\
\text { Historically formed infrastructure } \\
\text { Cargo and passenger traffic }\end{array}$ & $\begin{array}{c}\text { Resource availability } \\
\text { Gravity }\end{array}$ \\
\hline & $\begin{array}{l}\text { Administrative } \\
\text { component }\end{array}$ & $\begin{array}{c}\text { Openness } \\
\text { Population concentration } \\
\text { Presence of the core/cores } \\
\text { Regional identity }\end{array}$ & $\begin{array}{c}\text { Polystructurality } \\
\text { Role in ensuring national security } \\
\text { Presence of a "frame" } \\
\text { Budget donation } \\
\text { "Pilot" character }\end{array}$ \\
\hline \multirow{2}{*}{ 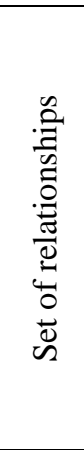 } & $\begin{array}{l}\text { Socio-economic } \\
\text { component }\end{array}$ & $\begin{array}{c}\text { Multidimensionality } \\
\text { Defining the role in the national economy } \\
\text { The concentration of industrial, trade and } \\
\text { service sectors } \\
\text { The concentration of intellectual and } \\
\text { human potential }\end{array}$ & $\begin{array}{c}\text { Low risks } \\
\text { High investment and innovation potential } \\
\text { Investment climate }\end{array}$ \\
\hline & Interactions & $\begin{array}{l}\text { High contact with neighbouring territories } \\
\text { Communicativeness } \\
\text { Attractiveness } \\
\text { Connectedness }\end{array}$ & $\begin{array}{c}\text { Space integration } \\
\text { Conjugate development } \\
\text { Resonant effects } \\
\text { Network interaction } \\
\text { Clustering }\end{array}$ \\
\hline
\end{tabular}

The selected topological attributes permit to characterise a region due to the phenomenon of "medianness", a unique economic and geographical position that acts as a catalyst for development. The median region can be considered a region that has the majority of quantitative characteristics. The above topological attributes will be studied in 32 regions of Russia.

To take into account the median factor of the region, it is proposed to make an integral estimate of the effect. By the cumulative effect of the regional median position, the authors understand the socio- economic efficiency of a territorial capital resulting from the advantages of the regional median position.

Let us consider the methodological tools for calculating the cumulative effect of the regional median position, including a system of indicators and the procedure for their integration.

$$
R_{m r}=\sqrt[n]{\prod_{i=1}^{n} R_{i}}
$$

where $R_{m r}$ - the cumulative effect of the regional median position; $R_{i}$ - effects that occur in certain areas (Table 2).

Table 2. A system of indicators for calculating the cumulative effect of the regional median position

\begin{tabular}{|c|l|l|}
\hline Indicator & $\begin{array}{c}\text { Effects by an area where } \\
\text { they occur }\end{array}$ & $\begin{array}{c}\text { Formula } \\
\text { for calculating the effect }\end{array}$ \\
\hline $\mathrm{R}_{1}$ & Effect in economy & $\frac{\text { Gross Regional Product / Region's investment volume }}{\text { Gross Domestic Product / Country's investment volume }} 100 \%$ \\
\hline $\mathrm{R}_{2}$ & Effect in regional budget & $\frac{\text { Consolidated budget / Region's investment volume }}{\text { Federal budget / Country's investment volume }} 100 \%$ \\
\hline $\mathrm{R}_{3}$ & Effect in innovation & $\frac{\text { Region's innovative products / Region's investment volume }}{\text { Russian Federation'sinnovative products / Country's investment volume }} 100 \%$ \\
\hline $\mathrm{R}_{4}$ & Effect in industry & $\frac{\text { Value added(VA) in the region's industry / The region's investment volume }}{\text { VA in industry / The country's investment volume }} 100 \%$ \\
\hline $\mathrm{R}_{5}$ & Effect in trade & $\frac{\text { VA in the region's trade / Region's investment volume }}{\text { VA in trade / Country's investment volume }} 100 \%$ \\
\hline $\mathrm{R}_{6}$ & Effect in construction & $\frac{\text { VA in the region's construction / Region's investment volume }}{\text { VA in the construction / Country's investment volume }} 100 \%$ \\
\hline
\end{tabular}




\begin{tabular}{|c|l|c|}
\hline Indicator & $\begin{array}{c}\text { Effects by an area where } \\
\text { they occur }\end{array}$ & $\begin{array}{c}\text { Formula } \\
\text { for calculating the effect }\end{array}$ \\
\hline $\mathrm{R}_{7}$ & $\begin{array}{c}\text { Effect on transport } \\
\mathrm{R}_{8}\end{array}$ & $\frac{\text { VA in the region's transport / Region's investment volume }}{\mathrm{VA} \text { in transport / Country's investment volume }} 100 \%$ \\
\hline $\mathrm{R}_{9}$ & Effect in education & $\frac{\text { VA in the region's healthcare / Region's investment volume }}{\text { VA in healthcare / Country's investment volume }} 100 \%$ \\
\hline
\end{tabular}

From a methodological point of view, the cumulative median effect is an excess of the key socio-economic indicators of the median region over the regional average. The median effect, due to the set of topological attributes of the median region, is manifested by a high economic return on investment.

\section{Results}

An analysis of the experience of developed and developing countries has shown that by the importance of the median regions in socio-economic development, three types of territories are distinguished: first, countries where the most "successful" regions are border territories (Brazil, India, etc.); second, countries where high indicators are shown by both median and border regions (USA, China, Kazakhstan, etc.); and third, countries where the median regions with high indicators have been formed (Russia, United Europe, etc.).

To conduct an empirical study in Russia, 32 regions were selected, classified as the median ones by their geographical position. Thus, $43.7 \%$ of the population lives in the territory of these entities; these entities account for $38.9 \%$ of Russian GDP, $64.2 \%$ of the volume of minerals production, $41.5 \%$ of the volume of investments in fixed assets, $44.7 \%$ of the volume of innovative products.

Verification of the median regions' transit has been made on the basis of the following indicators: the volume of goods sent by rail; the number of passengers sent by rail; the density of railway tracks; the density of paved roads; the volume of goods transported by road; the cargo turnover of road transport; the share of migration inflow from other regions; the share of internal migration inflow; the share of migration outflow to other regions; the coefficient of migration growth per 10,000 people.

The results have shown the following. Such indicators as the density of railway tracks and paved roads are not an indicator typical for the median regions. Only 4 median regions in Russia are included in the top 20 regions with a high density of transport networks. The factor associated with the transit of passengers transported by rail turned out to be insignificant (the share of the median regions accounts for only $18.4 \%$ of traffic). The study has confirmed the significance of such indicators in determining the median factor as the volume of rail transport (the share of the median regions is $68.3 \%$ ), cargo transportation by road (the share of the median regions is $27.9 \%$ ), and cargo turnover of road transport (the share of the median regions is $36.2 \%$ ).

Verification of the median regions' polystructurality has been made using the indicator of the number of municipalities. It has been determined that among the top 20 regions of Russia with the highest number of municipalities, 14 regions belong to the median ones. Tatarstan has the largest value among the median regions - 956 municipalities, and the Sverdlovsk Region has the least value - 94 municipalities.

Verification of the scale attribute has been performed using the territory's area. Half of the regions with an area above the average for Russia belong to the median regions.

The resource availability attribute has been verified based on the volume of mineral extraction. The top 20 regions of Russia with a high value of this indicator include 13 median regions, and all median regions account for $41.5 \%$ of the production volume.

The gravity attribute has been checked using the indicators of population migration and interregional trade turnover. It was found out that population migration indicators could not be the median characteristic. Only 6 median regions are attractive to other regions' population (the share of migrants is $40-42 \%$ ), while other median regions are localised 7 median regions are in the top 10 in terms of the share of intraregional migrants in the number of arrivals.

The population concentration attribute has not been confirmed during the study. Out of the top 20 regions of Russia with a high population density per $1 \mathrm{sq} . \mathrm{km}$, only 3 are the median ones.

The attribute of the role in ensuring national security has been checked using the following indicators: the concentration of enterprises in the military-industrial complex; the number of enterprises with foreign capital participation. The 
analysis has shown that such segments of the military-industrial complex as the production of ammunition, the radio-electronic industry, the production of general types of weapons, and the aviation industry are concentrated in the territory of the median regions. A significant number of organisations with foreign capital (68.7\%) are located in non-median regions. In 19 regions, the number of foreign companies is higher than the average for Russia, but only 5 of them are the median regions. Long-term observations of enterprises in Russia made it possible to identify preconditions for gazelle enterprises to appear and factors that prevent them from the sustained growth with an emphasised importance of some internal factors in these processes like entrepreneurs' personality traits in particular $[20,21]$.

The attribute of the median regions' budget donation has been fully confirmed. When analysing the budget for 2017-2019, it was found that there were no median regions among the subsidised regions; among the donor regions, $58.5 \%$ were the median ones.

The attribute of the "pilot" character in the median regions has been confirmed on the basis of data on the participation of regions in pilot projects of federal significance. The analysis has shown that in the "Standard of Personnel Support for Industrial Growth" project of 12 pilot regions are the missed number; in the "National Technology Initiative" project, out of 10 pilot regions 7 are the median ones; among 34 regions that received support for pilot projects from the Single-Industry Development Fund, 23 are classified as the median ones; among the pilot projects supported by the Industrial Development Fund, the median regions account for $37.4 \%$ of projects.

The attribute of the median regions' defining role in the national economy has been confirmed on the basis of indicators characterising the share of the median regions in the population, the volume of
GDP, investment in fixed assets, research and development costs, and the volume of innovative products.

The attribute of the intellectual capital concentration in the median regions has been confirmed using the indicator of the number of employees engaged in research and development. Thus, 11 out of 20 regions with a high value of this indicator are the median ones.

The attribute of low investment risks has been confirmed by the data of the RA Expert [22] regular rating. The attribute of a high investment and innovation potential has been confirmed using the following indicators: internal expenditures on research and development; the volume of innovative products; investment in fixed assets; rating of investment potential (RA Expert). The analysis permitted to conclude that in the top 20 regions of Russia in terms of these indicators, more than half are the median regions.

The attribute of high contact between the median regions and neighbouring territories has been checked using data on interregional trade. Thus, $84.2 \%$ of exports and $96.1 \%$ of imports of products fall in the median regions located in the Central, Volga, Ural and Siberian Federal Districts of Russia. In the agri-food sector, these links are more pronounced [23, 24].

The clustering attribute has been checked using the localisation coefficient, which characterises the ratio of the industry share in the region to the industry share in the country. Among regions with an indicator value greater than 1 , the median regions account for $36.5 \%$ in agriculture, $51.2 \%$ in mineral production, $52.0 \%$ in manufacturing, $41.5 \%$ in energy, and $40.3 \%$ in transport.

According to the authors, the set of metric attributes allows fully taking into account the regional median factor. The median region can be considered a region that has the majority of quantitative characteristics (Table 3).

Table 3. Results of verifying attributes of the median region

\begin{tabular}{|c|c|c|c|}
\hline Type & Attribute group & Attributes of the median region & Verification result \\
\hline \multirow{9}{*}{ 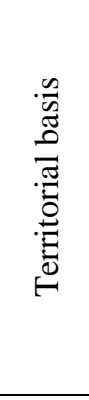 } & \multirow{5}{*}{ Spatial extent } & Transit: cargo and passenger traffic & Partially confirmed \\
\hline & & Polystructurality & Confirmed \\
\hline & & Scale & Confirmed \\
\hline & & Resource availability & Confirmed \\
\hline & & Gravity: interregional trade turnover, migration & Partially confirmed \\
\hline & \multirow{4}{*}{$\begin{array}{l}\text { Administrative } \\
\text { component }\end{array}$} & Population concentration & Not confirmed \\
\hline & & Role in ensuring national security & Confirmed \\
\hline & & Budget donation & Confirmed \\
\hline & & "Pilot" character & Confirmed \\
\hline
\end{tabular}




\begin{tabular}{|c|c|c|c|}
\hline Type & Attribute group & Attributes of the median region & Verification result \\
\hline \multirow{6}{*}{ 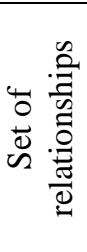 } & \multirow{4}{*}{$\begin{array}{l}\text { Socio-economic } \\
\text { component }\end{array}$} & Defining role in the national economy & Confirmed \\
\hline & & Intellectual potential concentration & Confirmed \\
\hline & & Low risks & Confirmed \\
\hline & & High investment and innovation potential & Confirmed \\
\hline & \multirow{2}{*}{ Interactions } & High contact with neighbouring territories & Confirmed \\
\hline & & Clustering & Confirmed \\
\hline
\end{tabular}

The results of the study suggest that the cumulative effect of the regional median position has a significant differentiation. Therefore, the authors can distinguish such types of median regions as integrators of the economic space, sustainable median regions, and developing median regions [25].

The median integrator regions are characterised by a high value of the cumulative effect, a high volume of cargo turnover, a high value of gravity for

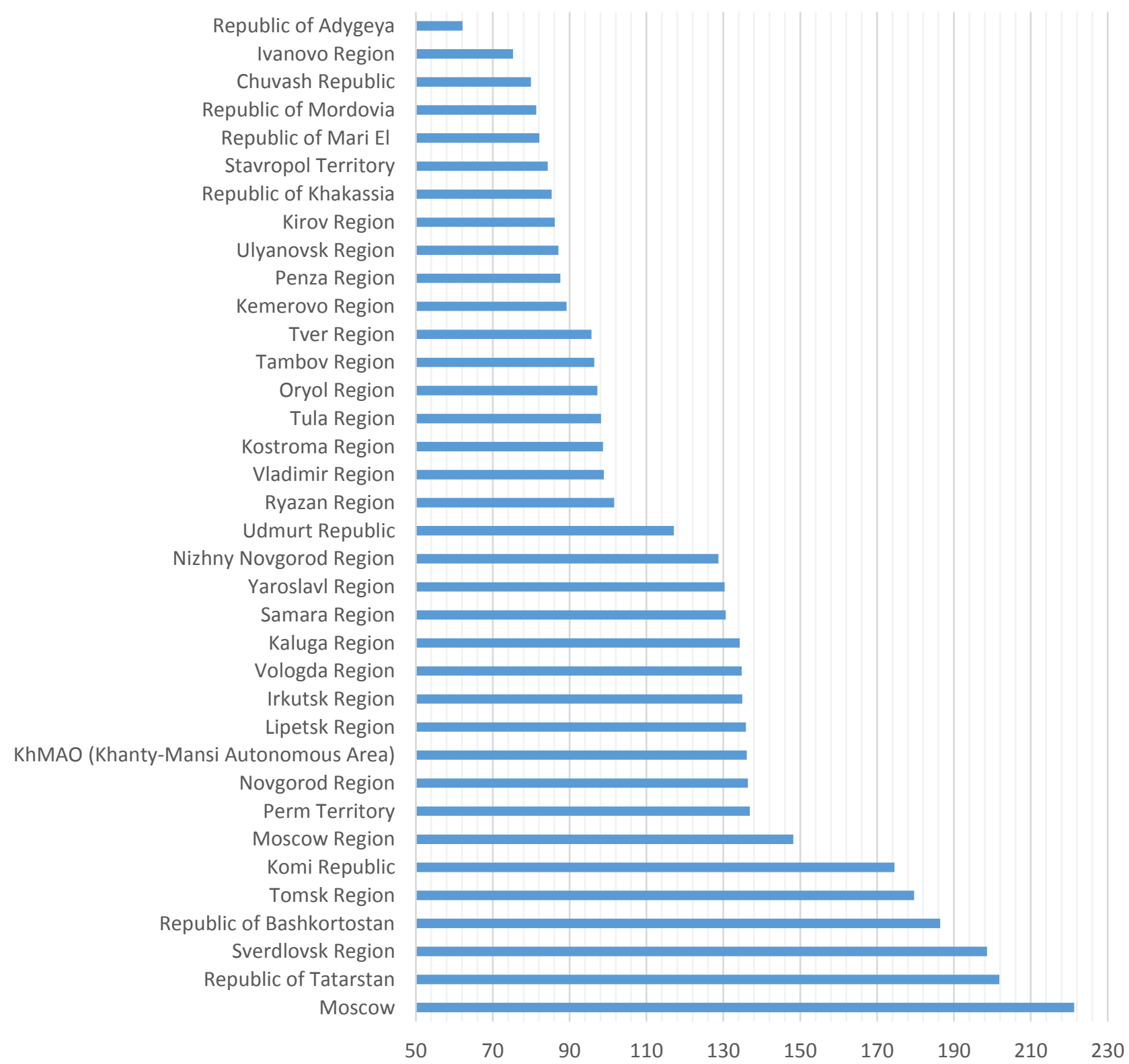

Fig. 1. The level of cumulative effect for the median regions in Russia interregional trade, a high share of neighbouring territories in the balance of interregional trade, and a high clustering coefficient. According to the estimates obtained, the following Russian regions are considered as integrator regions: Moscow, the Republic of Tatarstan, the Republic of Bashkortostan and the Komi Republic, the Sverdlovsk and Tomsk Regions. These regions have a cumulative effect value of more than $150 \%$ (Fig. 1). 
The features of sustainable median regions reflect such characteristics as a high value of the cumulative effect, high investment, innovation, and budget potentials, low business risks, and "pilot" character. Based on the calculations, this group includes the Moscow, Novgorod, Lipetsk, Irkutsk, Vologda, Nizhny Novgorod, Kaluga, Ryazan, Samara, and Yaroslavl Regions, Perm Territory, Khanty-Mansi Autonomous Area and the Udmurt Republic. The value of the cumulative median effect is in the range of $101.6-148.2 \%$.

The developing median regions are characterised by low values of the cumulative effect, indicators of investment, innovation and budget potential, and high business risks. This group includes the following Russian regions: the Vladimir, Kostroma, Tula, Oryol, Tambov, Tver, Kemerovo, Penza, Ulyanovsk, Kirov, and Ivanovo Regions, the Republics of Khakassia, Mari El, Mordovia, Adygeya, the Chuvash Republic and Stavropol Territory. The value of the cumulative median effect is in the range of $62.1-98.9 \%$.

Based on the highlighted topological attributes, the authors were able to describe the mission of median regions, taking into account the fundamental aspects of their development. The mission of median regions is to transform the territories into integrators of the country's socio-economic space through network interaction [26]. It may be concluded that median regions are also impulsive regions due to their system-forming functions and topological attributes.

\section{Conclusions}

On the basis of the literature review, we substantiated an approach to the definition of the middle region, containing a characteristic of the territorial position, and a system of interactions in the socio-economic space of the state.

The socio-economic development of the median regions shows relatively stable dynamics due to the current historical location in the country's territorial structure. It is substantiated that the factor of the medianness of the region can be of key importance in regional policy only if this resource is used correctly in program activities, regional development strategies and regional policy of the state.

The predominant attribute group of the median regions is considered to be the territorial basis (which includes the attributes of scale, transit, infrastructure, as well as resource availability and gravity). In addition to the decisive role in the national economy, the concentration of the industrial and trade and service sectors, intellectual and human potential, for the median regions, it is also possible to note the attribute of low risks, high innovation potential, and a favourable investment climate.

The results of the study suggest that the cumulative effect of the regional median position has a significant differentiation. Therefore, such types of median regions as integrators of the economic space, sustainable median regions, and developing median regions can be identified.

\section{References:}

[1] Rodoman, B.B. Territorial Areas and Networks, Smolensk, 2012.

[2] Losch, A. Die räumliche Ordnung der Wirtschaft, Jena, 1944.

[3] Weber, A. Über den Standort der Industrien, Tübingen, 1909.

[4] Christaller, W. Die zentralen Orte in Süddeutschland, Jena, 1933.

[5] Animitsa, E.G., Dvoryadkina, E.B., Novikova, N.V. et al. Region in the Socio-Economic Space of Russia: Analysis, Dynamics, Management Mechanism, Perm: PSU, 2008.

[6] Isard, W. Methods of Regional Analysis: An Introduction to Regional Science, New York, 1960.

[7] Kuklinski, E. Regional development - the beginning of a turning point, Regional Development and Cooperation, No. 10, 1997.

[8] Pchelintsev, O.S. Economic Justification of the Allocation of Productive Forces, Moscow, 1966.

[9] Granberg, A.G. Fundamentals of Regional Economy, Moscow: Higher School of Economics, 2000.

[10] Friedmann, J. Regional Development Policy, Boston: Massachusetts Institute of Technology, 1966.

[11] Friedmann, J. Regional development as a policy issue, in J. Friedmann \& W. Alonso, Regional Development and Planning, Cambridge (Mass.), 1964, pp. 18-32.

[12] Makreshanska-Mladenovska, S. \& Petrevski, G. Decentralization, fiscal transfers and income inequality in Central and Eastern European Countries, Journal of Eurasian Economic Dialogue, Vol. 2, No. 6, 2017, pp. 44-54.

[13] Gritsay, O.V., Ioffe, G.V. \& Treivish, A.I. The Centre and the Periphery in Regional Development, Moscow, 1991.

[14] Animitsa, E.G. \& Glumov, A.A. The Middle Region: Theory, Methodology, Analysis, YekaterinburgЖ Publishing House of the Ural State University of Economics, 2007. 
[15] Tatarkin, A.I. Socio-economic status of the middle region of Russia, Regional Economy, No. 2, 2005, pp. 5-22.

[16] Pavlov, K. Economic management based on accounting for reproductive imbalances, Problems of Theory and Practice of Management, No. 3, 2009, p. 41.

[17] Shniper, R.I. Region: Diagnostics and Forecasting, Novosibirsk: Institute of Economics and Industrial Engineering of the Siberian Branch of the RAS (IEOPP SB RAS), 1996.

[18] Maevsky, V.I. Mesolevel and hierarchical structure of the economy, Journal of Institutional Studies, Vol. 10, no. 3, 2018, pp. 18-29.

[19] Brodskaya, T.G. Balance of Regional Reproduction, Leningrad: LFEI Publishing House, 1991.

[20] Litau, E. "Evolution of species" in business: From mice to elephants. The question of small enterprise development, Journal of Advanced Research in Law and Economics, Vol. 8, No. 6, 2017, pp. 1812-1824. Available at: https://doi.org/10.14505/jarle.v8.6(28).16

[21] Litau, E. (2018). The information problem on the way to becoming a "Gazelle", In Proceedings of the European Conference on Innovation and Entrepreneurship, ECIE, 2018, September, pp. 394-401.

[22] "RA Expert" Rating Agency. Available at: https://raexpert.ru

[23] Chernova, V.Y., Golodova, Z.G., Degtereva, E.A., Zobov, A.M. \& Starostin, V.S. Transregional coordination of modernization processes in implementation of importsubstituting policy in Russia, European Research Studies Journal, Vol. 21, No. 4, 2018, pp. 887-898.

[24] Chernova, V.Y., Andronova, I.V, Degtereva, E.A., Zobov, A.M. \& Starostin, V.S. (2019). Activity of Russian companies of the agri-food sector in regional industrial value-added chains, Advances in Systems Science and Applications, Vol. 19, No. 1, pp. 31-43.

[25] Akberdina, V.V. \& Sergeeva, A.S. (2020). Strategic priorities for the development of middle regions in Russia, $R$-Economy, 6(2), 2020, pp. 89-99.

[26] Akberdina, V.V. \& Sergeeva, A.S. (2018). Substantiation of the system of indicators for an evaluation of the median factor in the regional aspect on an example of a median region, Regional Problems of Economic
Transformation, Vol. 6, No. 92, 2018, pp. 8697.

[27] Jacob, J., \& Hasan, N. (2016). Determining the centers of economic growth and regional development using scalogram analysis (An empirical study in west Halmahera regency, Indonesia). IOSR Journal of Economics and Finance, Vol. 7, No. 4, pp. 31-36. https://doi.org/10.9790/5933-704033136

[28] Wijaya, A., Darma, S., \& Darma, D.C. (2020). Spatial interaction between regions: Study of the East Kalimantan Province, Indonesia. International Journal of Sustainable Development and Planning, Vol. 15, No. 6, pp. 937-950. https://doi.org/10.18280/ijsdp.150618

[29] Wahyuningsih, D., Yunaningsih, A., Priadana, M.S., Wijaya, A., Darma, D.C., \& Amalia, S. (2020). The dynamics of economic growth and development inequality in Borneo Island, Indonesia. Journal of Applied Economic Sciences, Volume XV, No 1(67), pp. 135-143. https://doi.org/10.14505/jaes.v15.1(67).12.

\section{Contribution of individual authors to the creation of a scientific article (ghostwriting policy)}

Victoria Akberdina: Formulation or evolution of overarching research goals and aims; Management and coordination responsibility for the research activity planning and execution; Provision of study materials.

Alyona Sergeeva: Development or design of methodology, creation of models; Application of statistical, mathematical, or other formal techniques to analyze or synthesize study data.

\section{Sources of funding for research presented in a scientific article or scientific article itself}

The article was prepared in accordance with the Research Plan of the Institute of Economics of the Ural Branch of the Russian Academy of Sciences.

\section{Creative Commons Attribution License 4.0 (Attribution 4.0 International, CC BY 4.0)}

This article is published under the terms of the Creative Commons Attribution License 4.0

https://creativecommons.org/licenses/by/4.0/deed.en_US 